\title{
Export, Foreign Direct Investment, and Local Content Requirement*
}

\author{
Larry D. Qiu ${ }^{\dagger}$ \\ Hong Kong University of Science and Technology \\ Zhigang Tao \\ The University of Hong Kong
}

Final version: March 2001

\begin{abstract}
Local content requirement is a popular government policy in developing countries to regulate foreign direct investment. We establish a model with heterogeneous multinational firms and show that (a) the LCR policy affects the firms' modes of entry to a new market, with FDI being more likely to be adopted for a lower LCR; and (b) when facing the same LCR, a less efficient firm is more likely to adopt the FDI mode than a more efficient firm. Furthermore, we investigate the design of optimal LCR policy. Two types of FDI benefit are considered, and two types of LCR policy are compared.
\end{abstract}

Key Words: Export, FDI, local content requirement, uniform LCR, discriminatory LCR, multinationals.

JEL Classification Numbers: F12, F13, F23.

* We thank Leonard K. Cheng, Sajal Lahiri, Kar-yiu Wong, and seminar participants at City University of Hong Kong, Hong Kong University of Science and Technology, and University of Tokyo, for their helpful comments. We are very grateful to the two anonymous referees, whose suggestions have led to substantial changes and improvements in the paper. We are grateful for financial support by a grant from the Research Grant Council of the Hong Kong Special Administrative Region, China (HKUST6214/00H).

$\dagger$ Correspondence to: Larry D. Qiu, Department of Economics, Hong Kong University of Science and Technology, Clear Water Bay, Kowloon, Hong Kong. Phone number: +(852)2358-7628. Fax number: +(852)2358-2084. Email: larryqiu@ust.hk. 
There is little chance that companies trying to do business in the developing world will escape this rising tide of local content demands.

Wall Street Journal (31 July 1984).

\section{Introduction}

The world is increasingly polarized between developed countries with superior technologies but saturating markets and developing countries with backward technologies but relatively unexplored markets. While firms from developed countries may prefer to export their products to the unexplored markets, developing countries attempt to use their market potential to attract foreign direct investment (FDI). This is because, in contrast to export, foreign direct investment by multinational enterprises (MNEs) may raise employment and enhance technology transfer in developing countries.

In order to fully realize the employment and technology-transfer benefit, developing countries commonly impose local content requirement (LCR) on FDI. As the LCR policy requires the multinational firms to use a certain proportion of locally made parts and components, employment in the local parts industries is bound to increase. Furthermore, to maintain the quality of their final products, it is also necessary for the multinational firms to transfer technology to the local parts industries. Thus, LCR becomes a popular government regulation of FDI in developing countries. ${ }^{1}$ As reported by UNIDO (1986, p. 10), in a sample of 50 countries, 27 (or $54 \%$ ), mostly developing countries, have LCR policies for FDI in the automobile industry alone in $1980 .^{2}$

Although LCR is an important policy with respect to FDI, it has received much less attention in the literature than policies directed at international trade. ${ }^{3}$ This paper is an attempt to

\footnotetext{
${ }^{1}$ For more discussion on the benefits of the LCR, see UNIDO (1986, pp. 6-7).

${ }^{2}$ The percentage of local inputs ranges from $15 \%$ to as high as $100 \%$. Detailed information can be found in Table 3 contained in UNIDO (1986). More recently, the LCR in the automobile industry was up to $60 \%$ in Malaysia (Financial Times, 16 May 1990), and as high as 80-90\% in China (Qiu, 1997).

${ }^{3}$ It is well recognized that the TRIMs (Trade Related Investment Measures) agreement under the
} 
analyze LCR policy. We first examine how LCR affects the multinational firms' modes of entry into a new market, i.e., export and FDI. We then investigate the design of optimal LCR policy.

While a tariff makes the export mode less attractive to multinationals than the FDI mode, the reverse holds for an LCR policy. We find that, when facing the same LCR policy, a less efficient multinational firm (in terms of the cost of production) is more likely to adopt the FDI mode than a more efficient one. Intuitively, the LCR policy pushes up the cost of production for multinational firms, as the locally made parts and components are of lower quality and higher cost. However, for a given LCR policy, the relative cost increase for the more efficient MNE is higher than that for the less efficient MNE. ${ }^{4}$ Thus, for a certain range of the LCR, we may see the more efficient MNEs choosing the export mode, and the less efficient ones the FDI mode.

The design of optimal LCR policy is complicated by the endogeneity of the multinationals' entry modes. As discussed above, the LCR policy makes it less likely for the multinational firms to choose the FDI mode than the export mode. Given that the multinational firms take the FDI mode, however, the LCR policy allows the host country to fully capture the employment and technology-transfer benefit of FDI. Meanwhile, the LCR policy adversely affects the consumer surplus, as it raises the cost of production for those MNEs that choose the FDI mode.

The host government cares about both the consumer surplus and the FDI benefit. While it is straightforward to define the consumer surplus, the specification of the FDI benefit can be complicated. For tractability of analysis, we assume two reduced forms of FDI benefit: (1) the host government cares exclusively about the employment created by the FDI in the upstream industries, and (2) the host government cares exclusively about the technology transfer

Uruguay Round will make LCR illegal in a few years. But this does not undermine the importance of studying LCR, for at least two reasons. First, compared with the trade policies, LCR receives much less scrutiny in the literature. Studying LCR will help us to understand the past and current state of FDI in developing countries. Second, it is very unlikely that the TRIMs agreement will be strictly enforced in the near future, especially in developing countries. Wonnacott (1996, p. 97) has well explained this latter concern. In fact, a recent meeting of the WTO heard requests from seven developing countries (Argentina, Chile, Malaysia, Mexico, Pakistan, the Philippines, and Romania) for an extension of the deadline, varying from five months to seven years, for trade restrictions on foreign investors (mainly LCR) in the vehicle sectors (Financial Times, 25 January 2000).

${ }^{4}$ The following hypothetical example illustrates this point. Suppose that without FDI, firm 1 spends $\$ 100$ and firm $2 \$ 200$ on components. The LCR policy requires that a firm must use at least $50 \%$ local parts, which costs $\$ 200$. As a result, with FDI, firm 1's cost becomes $\$ 250$, a $150 \%$ increase, and firm 2's cost becomes $\$ 300$, a $50 \%$ increase. 
accomplished by the FDI in the upstream industries. In our analysis of optimal LCR policy, we consider both the discriminatory LCR policy, which allows for different degrees of LCR to different firms, and the uniform LCR policy, which applies the same degree of LCR to all firms.

The basic results can be summarized as follows. If the LCR is constrained to be uniform and the employment benefit is the main concern, then large cost differences between multinationals result in an LCR that induces the more cost-efficient firm to export and the less cost-efficient firm to choose FDI; for small cost differences, the optimal LCR induces both firms to choose FDI. If the technology benefit is the main concern, then the optimal uniform LCR leads to both firms choosing FDI. However, the optimal discriminatory LCR always induces both firms to choose FDI. The LCR is larger on the less efficient firm if the employment benefit is most important; but it may be larger on the more efficient firm if the technology benefit is most important. These results bear strong empirical implications.

There is a growing literature on the LCR. Grossman (1981) systematically analyzes the effects of content protection on resource reallocation, with a particular focus on the intermediate goods. He finds that a conclusion about the degree of protection that the LCR gives to domestic intermediate goods is hard to reach, as it depends on the substitution possibilities in production, the supply conditions in the domestic intermediate-good industry, and the market structure for that good. Most recently, Lahiri and Ono (1998) have focused on the welfare implication of FDI and investigated the host country's optimal policy combination, which includes a profit tax/subsidy and an LCR on FDI. They characterize the optimal LCR policy, which depends on the number of domestic firms, the number of foreign MNEs, and the firms' costs. They find that it is optimal to tax the profits of the foreign MNEs if and only if the local costs are higher than twice the foreign costs. In contrast with these studies, our study explores why and how LCR affects MNEs' FDI-export decisions differently, and how the host government designs an optimal LCR policy on FDI from heterogenous foreign firms. Grossman (1981) assumes a competitive final-good market, and Lahiri and Ono (1998) assume identical foreign MNEs. Hence, their models necessarily exclude the issues investigated in the present paper. ${ }^{5}$

\footnotetext{
${ }^{5}$ In between Grossman (1981) and Lahiri and Ono (1998), there are also some other studies related to LCR, which include Davidson, Matusz, and Kreinin (1985), Hollander (1987), Krishna and Itoh (1988),
} 
Researchers in international business and international trade have attempted to explain why MNEs invest abroad, instead of exporting their products or licensing their technologies to foreign countries. ${ }^{6}$ According to Dunning $(1977,1981)$, an MNE will choose FDI over export and licensing if there are ownership advantage, location advantage, and internalization advantage. Because these factors vary from country to country and from industry to industry, we can easily observe that different countries attract different amounts of FDI, as do different industries in the same country. It is equally transparent that MNEs from different countries or different industries have different incentives to make FDI. ${ }^{7}$ In this paper, we explain why MNEs in the same industry adopt different modes (i.e., FDI and export) to enter the same market. ${ }^{8}$ We show that, other things being equal, firms that differ in production cost will realize different levels of FDI location advantage and thus may adopt different entry modes. ${ }^{9}$

There are two distinguishing features in our model. First, we consider a more realistic case in which the final good is tradable, whereas previous studies in the literature have essentially assumed that the final good is nontradable. This feature allows us to examine LCR's influence on MNEs' choice of entry modes. Second, while the literature typically assumes identical foreign firms, we consider heterogeneous foreign firms. This unique feature opens up the opportunity for us to explain the different entry modes adopted by different MNEs, and to derive different optimal LCR policies for different foreign firms (i.e., the discriminatory LCR).

Richardson (1991, 1993), Chao and Yu (1993), and Lopez-de-Silanes, Markusen, and Rutherford (1996). However, none of them considers asymmetric entry modes and optimal LCR policy. See Belderbos and Sleuwaegen (1997) for a very brief survey.

${ }^{6}$ The literature on MNEs and FDI is very large and still growing. Early contributions were made by researchers in the field of international business, including Hymer (1976), Dunning (1977, 1981), and Caves (1982). International economists have also contributed to this literature, particularly with formal economic models. They include Helpman (1984), Markusen (1984), Ethier (1986), Horstmann and Markusen (1987, 1992, 1995), Brainard (1993), and Ethier and Markusen (1996). Markusen (1995) has a nice survey of the literature, paying particular attention to research and models produced by international economists.

${ }^{7}$ In their empirical study, Mody and Srinivasan (1998) find that the Japanese MNEs and the U.S. MNEs behave differently in their FDIs. Feinberg, Keane, and Bognanno (1998) find that the U.S. MNEs that have invested in Canada respond to Canadian tariff changes differently.

${ }^{8}$ See Qiu (1997) for such examples in China's automobile industry.

${ }^{9}$ Internalization advantage is used to explain the choice of FDI over licensing. Ownership advantage is a necessary, but not sufficient, condition for choosing FDI over export. Since we only compare FDI and export modes and we know that all foreign automakers have ownership advantage, we can just focus on the location advantage. 
The rest of the paper is organized as follows. In Section 2, we lay out the model and analyze asymmetric MNEs' responses to LCR. In Section 3, we discuss the framework for optimal policy analysis. We analyze the optimal discriminatory LCR policy in Section 4, and the optimal uniform LCR policy in Section 5. Our concluding remarks are given in Section 6.

\section{The Choice between FDI and Export}

Suppose there are two multinational enterprises, henceforth referred to as firm 1 and firm 2. They produce a homogeneous product and consider entry to the market of a developing country, called the host country. Each firm can enter the market via export or FDI. ${ }^{10}$ To focus on the multinationals' choices of entry mode, we assume away any local competitor in the market for the final product. ${ }^{11}$ Demand in the host market is characterized by $P=P\left(q_{1}+q_{2}\right)$, where $q_{i}$ is the quantity produced by firm $i(i=1,2)$ and $P(\cdot)$ has the usual properties.

In modern manufacturing industries such as the automobile industry, a final product is assembled from a set of parts and components. Thus the production cost includes the cost of parts and components and that of assembly. To facilitate our analysis of the LCR policy, we only consider the cost of parts and components. Specifically, we assume that there is no fixed cost of production and each firm's marginal cost of parts and components (denoted by $c_{i}$ ) is constant. Thus, $c_{i}$ is firm $i$ 's unit cost of production. Without loss of generality, we assume that firm 1 is more cost-efficient than firm 2: $c_{1}<c_{2}$.

If firm $i$ chooses to export its product to the new market, it pays an additional cost per unit of output, denoted by $t$. This cost includes transportation cost and trade barriers (tariff and nontariff). Henceforth, $t$ is referred to as the cost of export.

If firm $i$ chooses to make FDI in the host country, then it needs to comply with the LCR policy imposed by the host government. An LCR policy specifies that a certain fraction, de-

\footnotetext{
${ }^{10}$ We exclude the possibility of licensing, and focus on the choice between export and FDI, which is overlooked in the existing literature on LCR. Specifically, Grossman (1981) does not analyze entry decisions, and Lahiri and Ono (1998) do not consider export and licensing.

${ }^{11}$ In the case of Volkswagen's FDI in China, "competition from other domestic car makers has yet to become the major threat to VW's business in China. More than domestic competition, VW feels it is imports that are having the biggest impact on sales, especially Japanese and South Korean cars." (EIU, 1996, p. 3.) In 1995, the Chinese market had 322,000 domestically made cars (more than $90 \%$ by Sino-foreign joint ventures) and 158,000 imported cars (EIU, 1997, p. 2).
} 
noted by $\lambda_{i} \in[0,1]$, of parts and components for the final-good production must be locally made. $^{12}$ Moreover, if the LCR is met, there is no tariff on the import of the remaining parts and components. Let $\bar{c}$ be the unit cost of production if a firm uses all local parts and components. For the LCR to be meaningful, assume that $\bar{c}$ is higher than $c_{1}$ and $c_{2} \cdot{ }^{13}$ Then, with the LCR policy, a firm choosing the FDI mode will only use the local parts and components up to $\lambda_{i}$ and import the rest from its home market, which implies its unit cost of production is $\lambda_{i} \bar{c}+\left(1-\lambda_{i}\right) c_{i}=c_{i}+\lambda_{i}\left(\bar{c}-c_{i}\right) .{ }^{14}$ Henceforth $\lambda_{i}\left(\bar{c}-c_{i}\right)$ is referred to as the cost of FDI.

For ease of exposition, we introduce an index function, $z_{i}$, to capture firm $i$ 's entry mode, with $z_{i}=0$ representing export and $z_{i}=1$ for FDI. Moreover, define

$$
\widetilde{c}_{i} \equiv \bar{c}-c_{i} \quad \text { and } \quad \lambda_{i}^{o} \equiv t / \widetilde{c}_{i}, \quad i=1,2
$$

Then, based on the above discussion, we obtain the unit cost function of firm $i$ as ${ }^{15}$

$$
C_{i} \equiv c_{i}+\lambda_{i} z_{i} \widetilde{c}_{i}+\left(1-z_{i}\right) t, \quad \text { where } \lambda_{i} \in[0,1] \text { and } z_{i}=\{0,1\}
$$

Accordingly, firm $i$ 's FDI cost is $\lambda_{i} z_{i} \widetilde{c}_{i}$, export cost is $\left(1-z_{i}\right) t$, and profit is $\pi_{i}=\left(P-C_{i}\right) q_{i}$.

Firms 1 and 2 play a two-stage game: at the first stage they choose the entry modes, and at the second stage they compete in the market by choosing their levels of output. There are four possible outcomes for the first stage of the game: (E, E), (E, I), (I, E), and (I, I), where E denotes export, I denotes FDI, and the first (second) component of a pair represents the entry mode of firm 1 (firm 2). We follow the backward induction principle by first considering the

\footnotetext{
${ }^{12}$ In practice, if a firm fails to meet the LCR, punitive tariffs could be levied on its imports of parts and components. We assume that the punitive tariffs are so high that the firm will never violate the LCR if it chooses the FDI mode.

${ }^{13}$ Both Grossman (1981) and Lahiri and Ono (1998) make this assumption without any justification. What we have in mind is that the locally produced parts and components are of lower quality than what firm 1 and firm 2 can obtain from their own markets. Consequently, the quality-adjusted unit cost of local parts and components is higher than $c_{1}$ and $c_{2}$.

${ }^{14}$ Lahiri and Ono (1998) also use this cost structure. Grossman (1981) distinguishes between an LCR defined in physical terms and one defined in value terms, since he wants to examine their different effects on the upstream industry. Nevertheless, determining local content in value terms is nebulous, as the figures can be manipulated by exaggerating the value of local parts and components. Grossman (1981) avoids this problem by assuming exogenous prices for both intermediate and final products.

${ }^{15}$ Both export and FDI involve some setup costs. However, the effects of these costs on a firm's choice of entry mode are obvious. To focus on more important issues, we omit these fixed costs in our model.
} 
quantity competition between the two firms given their entry modes and then investigating the equilibrium entry modes.

Given the entry modes of the first stage, i.e., $\left(z_{1}, z_{2}\right)$, the firms engage in a Cournot competition at the second stage. The equilibrium output levels are determined by the following first-order conditions:

$$
P^{\prime} q_{i}+P-C_{i}=0, \quad i=1,2
$$

Total differentiation yields the result that a firm's equilibrium output (denoted by $q_{i}^{*}$ ) decreases with its own unit cost of production but increases in its rival firm's unit cost of production: ${ }^{16}$ $\partial q_{i}^{*} / \partial C_{i}<0$ and $\partial q_{i}^{*} / \partial C_{j}>0$, where $i$ or $j=1,2$ and $i \neq j$.

Using the envelope theorem, we can also show that the equilibrium profit of a firm $\left(\pi_{i}^{*}\right)$ decreases with its unit cost of production, specifically,

$$
\frac{\partial \pi_{i}^{*}}{\partial C_{i}}=q_{i}^{*}\left(P^{\prime} \frac{\partial q_{j}^{*}}{\partial C_{i}}-1\right)<0 .
$$

Intuitively, raising cost lowers profit directly and also through increasing the competitor's output. Note further that this result holds regardless of whether or not the competitor takes the export mode or the FDI mode. It follows that each firm chooses the lower-cost mode of entry regardless of the competitor's choice of entry mode. Recall that firm $i$ 's unit cost is $c_{i}+\lambda_{i}\left(\bar{c}-c_{i}\right)$ in the case of FDI and $c_{i}+t$ in the case of export. If the cost of FDI is higher than that of export, i.e., $\lambda_{i}\left(\bar{c}-c_{i}\right)>t$, then it is optimal for firm $i$ to choose export (or $z_{i}=0$ ). Otherwise, it is optimal for firm $i$ to choose FDI (or $z_{i}=1$ ). ${ }^{17}$ We summarize the above analysis with the following proposition:

Proposition 1: Firm $i$ chooses FDI as its optimal entry mode (i.e., $z_{i}=1$ ) if and only if $\lambda_{i} \leq \lambda_{i}^{o}$. Under the uniform LCR policy in which $\lambda_{1}=\lambda_{2} \equiv \lambda$ and given that $t$ is not too big, we will observe the following equilibrium outcomes sequentially: (E, E), (E, I), and (I, I), as $\lambda$ decreases from one to zero.

\footnotetext{
${ }^{16}$ We assume downward-sloping reaction curves and satisfaction of the stability conditions, which are $P^{\prime \prime} q_{i}+2 P^{\prime}<0, P^{\prime \prime} q_{i}+P^{\prime}<0$, and $A \equiv\left(P^{\prime \prime} q_{1}+2 P^{\prime}\right)\left(P^{\prime \prime} q_{2}+2 P^{\prime}\right)-\left(P^{\prime \prime} q_{1}+P^{\prime}\right)\left(P^{\prime \prime} q_{2}+P^{\prime}\right)>0$. Then $\partial q_{i}^{*} / \partial C_{i}=\left(P^{\prime \prime} q_{j}+2 P^{\prime}\right) / A<0$ and $\partial q_{i}^{*} / \partial C_{j}=-\left(P^{\prime \prime} q_{i}+P^{\prime}\right) / A>0$.

${ }^{17}$ We assume that a firm will choose FDI when it is indifferent between export and FDI.
} 
If there is only one firm contemplating entry to a new market, it is clear that its choice between export and FDI depends upon their relative cost. However, it is interesting to note that, even when there are two firms, one firm's entry mode is independent of the other firm's. While this result is obtained under several simplifying assumptions, the intuitive appeal of this result is quite strong.

The equilibrium outcome is determined by the interplay of the export cost $(t)$ and the LCR policy $\left(\lambda_{i}\right)$. Given an LCR, a firm is more likely to choose FDI over export if the export cost is higher. This result is exactly the same as the "tariff-jumping" argument for FDI, which has been discussed extensively in the literature. What is less understood is the effect of LCR policy on the equilibrium entry mode.

Note that a higher LCR makes it less likely for a firm to choose the FDI mode. This is because the FDI cost comes from the mandatory use of expensive local parts and components, and it increases in the level of LCR. Given that the export cost is fixed, a firm switches its entry mode from FDI to export as the LCR increases from zero to one. Furthermore, the level of LCR at which firm 1 (the more cost-efficient firm) switches from FDI to export is lower than that for firm 2 (formally, $\lambda_{1}^{o}<\lambda_{2}^{o}$ ). Intuitively, because without LCR firm 1's cost is lower than firm 2's cost, the cost increase from using any given percentage of expensive local parts and components is higher for firm 1 than firm 2. Hence, in the case of uniform LCR policy, there exists an intermediate range of $\lambda$ satisfying $\lambda \widetilde{c}_{1}>t \geq \lambda \widetilde{c}_{2}\left[\right.$ or $\left.\lambda \in\left(t / \widetilde{c}_{1}, t / \widetilde{c}_{2}\right]\right]$ under which firm 1 chooses the export mode but firm 2 takes the FDI mode. It is worth pointing out that, in this case, the firm choosing FDI is the less cost-efficient one, which may not be desirable from the host government's point of view and can be avoided if the discriminatory LCR policy is adopted.

\section{A Framework for Analyzing Optimal LCR Policy}

We have analyzed how the multinational firms choose between export and FDI given the LCR policy. In the rest of the paper, we investigate the design of optimal LCR policy from the host government's point of view. To sharpen the focus, we reinterpret the export cost $t$ as an exogenous transportation cost. The host government chooses the LCR to maximize its social 
welfare consisting of FDI benefit and consumer surplus. ${ }^{18}$

While it is straightforward to define the consumer surplus, the specification of the FDI benefit can be complicated. A detailed analysis would involve modeling of the FDI process. A multinational firm may simply set up an assembly line in the host country and buy low-quality parts and components from the local industries. Or it may get more involved by licensing technologies to the local parts and components industries. ${ }^{19}$ In the former case, the benefit of FDI to the host country is the employment generated in the parts and components industries. In the latter case, the benefit includes not only the employment but also the technology transfer in the upstream industries.

To make our analysis of optimal LCR policy tractable, however, we assume two reduced forms of FDI benefit. First, the host government cares about the employment generated by the FDI. Given that each unit of output from FDI requires a certain amount of local input $\left(\lambda_{i} \bar{c}\right)$, this FDI benefit can be proxied by $\lambda_{1} \bar{c} z_{1} q_{1}+\lambda_{2} \bar{c} z_{2} q_{2}$. Second, the host government cares about the technological upgrading provided by the FDI. In this case, the FDI benefit can be proxied by the technological gap between the multinationals and the local parts industries, and is assumed to take the form $\lambda_{1} \widetilde{c}_{1} z_{1} q_{1}+\lambda_{2} \widetilde{c}_{2} z_{2} q_{2}$. In summary, the host government's welfare function is

$$
W\left(\lambda_{1}, \lambda_{2}\right)=s \times F D I \text { Benefit }+ \text { Consumer Surplus, }
$$

where the FDI benefit can be either $\lambda_{1} \bar{c} z_{1} q_{1}+\lambda_{2} \bar{c} z_{2} q_{2}$ or $\lambda_{1} \widetilde{c}_{1} z_{1} q_{1}+\lambda_{2} \widetilde{c}_{2} z_{2} q_{2}$, the consumer surplus is $\int_{0}^{q_{1}+q_{2}}\left[P(Q)-P\left(q_{1}+q_{2}\right)\right] \mathrm{d} Q$, and $s$ is the weight placed by the host government on the FDI benefit relative to the consumer surplus. ${ }^{20}$

\footnotetext{
${ }^{18}$ Lahiri and Ono (1998) also include the FDI benefit in the host government's welfare function. In the present paper profits are not shown in the welfare function, as there is no domestic producer of final product.

${ }^{19}$ See Woodard and Zhu (1994) and EIU (1997) for examples. Technology transfer helps to improve the quality of locally made parts and components. However, the cost may remain high, as if there were no technology transfer, because the multinational firm can be expected to adjust its licensing fee to reflect the technological gap.

${ }^{20}$ We can treat such a welfare function as the reduced form of government welfare derived from a political-economy framework [Grossman and Helpman (1994)]. Then $s$ can be reinterpreted as the weight that the government places on lobbying by the special interest group: workers (in the case of employment) or the upstream industries (in the case of technological upgrading). We thank a referee for suggesting this political-economy interpretation of the welfare function.
} 
The government chooses $\lambda$ 's to maximize its social welfare. To derive the optimal LCR policy, we need to know how the $\lambda$ 's affect the firms' entry modes, which was studied in Section 2 and summarized in Proposition 1. We also need to know how the $\lambda$ 's affect the equilibrium outputs. For simplicity of analysis, we assume a linear demand curve, $P=a-b\left(q_{1}+q_{2}\right)$, where $a$ and $b$ are positive constants with $a$ being sufficiently large. ${ }^{21}$ Then, using the first-order condition (1), we can derive the Cournot equilibrium outputs and the consumer surplus (denoted by $C S$ ):

$$
q_{1}=\frac{a-2 C_{1}+C_{2}}{3 b}, q_{2}=\frac{a-2 C_{2}+C_{1}}{3 b}, \text { and } C S=\frac{b\left(q_{1}+q_{2}\right)^{2}}{2} .
$$

Depending on how $\lambda$ 's affect $C$ 's, we can determine the effects of $\lambda$ 's on $q$ 's and subsequently the consumer surplus.

Our analysis of optimal LCR policy is organized as follows. In Section 4 we analyze the discriminatory LCR policy in which $\lambda_{1}$ can be different from $\lambda_{2}$; in Section 5 we examine the uniform LCR policy $\left(\lambda_{1}=\lambda_{2}\right)$. In each case, we investigate how the optimal LCR policy will differ if the host government mostly cares about the employment benefit of FDI from that if it mostly cares about the technological catching-up effect. We also highlight the differences between the optimal discriminatory and uniform LCR policies.

\section{Discriminatory LCR Policy}

We first derive in Section 4.1 the optimal discriminatory LCR policy when the host government is mainly concerned about the employment benefit and then derive in Section 4.2 the one when the government cares mostly the technology transfer benefit. A comparison of the two optimal policies and its implications for the implementability and testability of the policies are briefly discussed at the end of this section.

\subsection{FDI benefit - employment}

When discriminatory LCR policy is used and the employment benefit is mostly concerned, the host government chooses $\lambda_{1}$ and $\lambda_{2}$ to maximize

$$
W\left(\lambda_{1}, \lambda_{2}\right)=s \times\left(\lambda_{1} \bar{c} z_{1} q_{1}+\lambda_{2} \bar{c} z_{2} q_{2}\right)+C S
$$

\footnotetext{
${ }^{21}$ It is not uncommon in the literature that specific demand functions are assumed for welfare analysis. See for example, Dixit (1988) and Markusen (1998).
} 
Recall from Proposition 1 that firm $i$ engages in FDI if $\lambda_{i} \leq \lambda_{i}^{o}$ and chooses export otherwise. ${ }^{22}$ Hence we have

$$
C_{i}=\left\{\begin{array}{ll}
\lambda_{i} \bar{c}+\left(1-\lambda_{i}\right) c_{i} & \begin{array}{l}
\text { for } \lambda_{i} \leq \lambda_{i}^{o}, \\
\text { otherwise }
\end{array} c_{i}+t
\end{array} \quad \text { and } \quad \frac{\partial C_{i}}{\partial \lambda_{i}}= \begin{cases}\widetilde{c}_{i} & \text { for } \lambda_{i} \leq \lambda_{i}^{o} \\
0 & \text { otherwise }\end{cases}\right.
$$

Only when a firm (say, firm $i$ ) adopts the FDI mode, then, is its cost of production adversely affected by the LCR. Firm $j$ 's cost of production is not directly affected by the LCR imposed on firm $i$. Consequently, for a higher $\lambda_{i} \in\left[0, \lambda_{i}^{o}\right]$, firm $i$ 's output shrinks while firm $j$ 's expands. Furthermore, it can be shown that as $\lambda_{i}$ increases, the total output $\left(q_{1}+q_{2}\right)$, or equivalently the consumer surplus, decreases for $\lambda_{i} \in\left[0, \lambda_{i}^{o}\right]$ and becomes constant for $\lambda_{i}>\lambda_{i}^{o}$. Formally,

$$
\frac{\partial C S}{\partial \lambda_{i}}= \begin{cases}-\widetilde{c}_{i}\left(q_{1}+q_{2}\right) / 3 & \text { for } \lambda_{i} \leq \lambda_{i}^{o} \\ 0 & \text { otherwise }\end{cases}
$$

Thus, if the host government cares exclusively about the consumer surplus, it should set $\lambda_{i}$ as low as possible.

Next we examine how $\lambda_{i}$ affects the FDI benefit. Differentiating the FDI benefit with respect to $\lambda_{i}$ yields

$$
\frac{\partial(F D I \text { Benefit })}{\partial \lambda_{i}}=\bar{c} z_{i} q_{i}-\lambda_{i} \bar{c} z_{i} \frac{2}{3 b} \frac{\partial C_{i}}{\partial \lambda_{i}}+\lambda_{j} \bar{c} z_{j} \frac{1}{3 b} \frac{\partial C_{i}}{\partial \lambda_{i}}
$$

The first two terms capture the effect of $\lambda_{i}$ on the FDI benefit contributed directly by firm $i$ : $\lambda_{i} \bar{c} z_{i} q_{i}$. The third term is the effect of $\lambda_{i}$ on the FDI benefit contributed directly by firm $j$ : $\lambda_{j} \bar{c} z_{j} q_{j}$. As discussed earlier, a higher $\lambda_{i} \in\left[0, \lambda_{i}^{o}\right]$ pushes up firm $i$ 's cost of production, which leads to higher output by firm $j$. Hence, this latter effect increases in $\lambda_{i}$. Nevertheless, recalling from Proposition 1 that $z_{i}=0$ for $\lambda_{i}>\lambda_{i}^{o}$, both effects disappear when $\lambda_{i}>\lambda_{i}^{o}$.

Based on the above analysis on consumer surplus and FDI benefit, it is clear that the host government should choose $\lambda_{i}^{*}$ within $\left[0, \lambda_{i}^{o}\right]$, where $i=1,2$. In other words, under the optimal discriminatory LCR policy, both firm 1 and firm 2 undertake FDI. The remaining analysis then is focused on the comparison between $\lambda_{1}^{*}$ and $\lambda_{2}^{*}$.

Note that with $z_{1}=z_{2}=1$, (5) can be simplified as

$$
\frac{\partial(\text { FDI Benefit })}{\partial \lambda_{i}}=\bar{c}\left(q_{i}-\frac{2}{3 b} \lambda_{i} \widetilde{c}_{i}+\frac{1}{3 b} \lambda_{j} \widetilde{c}_{i}\right)
$$

\footnotetext{
${ }^{22}$ To make our analysis interesting, we assume $\lambda_{2}^{o}<1$ or equivalently $t<\widetilde{c}_{2}$.
} 
It can be easily checked that $\partial(F D I$ Benefit $) / \partial \lambda_{i}$ is decreasing in $\lambda_{i}$, being positive for small $\lambda_{i}$ but negative for large $\lambda_{i}$. When deciding on the specific level of $\lambda_{i}^{*}$, the host government weighs the marginal benefit of raising $\lambda_{i}$ [i.e., $s \times \partial(F D I$ Benefit $) / \partial \lambda_{i}$ ] against its marginal cost (i.e., $\left.\partial C S / \partial \lambda_{i}\right)$. At the optimal $\lambda_{i}^{*}$, the marginal benefit equals the marginal cost. Note that the marginal benefit of raising $\lambda_{i}$ is positively correlated with the parameter $s$, while its cost is independent of $s$. Hence the optimal $\lambda_{i}^{*}$ increases in $s$. Specifically, if $s$ is below some minimum level of $s$, the marginal benefit of raising $\lambda_{i}$ is always lower than the marginal cost. This calls for setting $\lambda_{i}$ as low as possible, i.e., $\lambda_{i}^{*}=0$. In contrast, if $s$ is above some maximum level of $s$, the marginal benefit of raising $\lambda_{i}$ is always greater than the marginal cost. This calls for setting $\lambda_{i}$ as high as possible, i.e., $\lambda_{i}^{*}=\lambda_{i}^{o}$. For moderate $s$, there exists a unique $\lambda_{i}^{*} \in\left(0, \lambda_{i}^{o}\right)$ such that the marginal benefit equals the marginal cost. Obviously, it is interesting to just focus on the comparison between $\lambda_{1}^{*}$ and $\lambda_{2}^{*}$ when both policies take interior solutions. In the Appendix (A), we characterize the conditions for moderate $s$.

Proposition 2: If employment is the main source of FDI benefit to the host country, then the optimal discriminatory LCR policy induces both multinational firms to undertake FDI, i.e., $\lambda_{i}^{*} \in\left[0, \lambda_{i}^{o}\right]$. Moreover, the optimal LCR for the more cost-efficient firm is lower than that for the less efficient firm, i.e., $\lambda_{1}^{*}<\lambda_{2}^{*}$.

Proof: See the Appendix (A).

The proposition says that the host government offers a more favorable (from the firm's point of view) LCR policy to the more cost-efficient firm. To understand this result, note that the (negative) marginal effect of raising $\lambda_{1}$ on consumer surplus [i.e., $\widetilde{c}_{1}\left(q_{1}+q_{2}\right) / 3$, from (4)] is higher than that of raising $\lambda_{2}$ [i.e., $\widetilde{c}_{2}\left(q_{1}+q_{2}\right) / 3$, from (4)]. Intuitively, since firm 1 is more efficient than firm 2, an increase in LCR leads to a higher cost increase for firm 1 than for firm 2. It follows that the total output reduction and consequently the consumer surplus decrease are more sensitive to an increase in firm 1's LCR than firm 2's LCR.

On the other hand, the (positive) marginal effect of raising $\lambda_{1}$ on the FDI benefit may or may not be lower than that of raising $\lambda_{2}$. However, the result in Proposition 2 indicates that the net welfare increase of raising $\lambda_{1}$ [i.e., $\partial(F D I$ Benefit $) / \partial \lambda_{1}-\partial C S / \partial \lambda_{1}$ ] is smaller than 
that of raising $\lambda_{2}$ [i.e., $\partial(F D I$ Benefit $\left.) / \partial \lambda_{2}-\partial C S / \partial \lambda_{2}\right]$.

\subsection{FDI benefit - technological upgrading}

We now consider the case where the host government cares about the technological catchingup effect of FDI and chooses $\lambda_{1}$ and $\lambda_{2}$ to maximize

$$
W\left(\lambda_{1}, \lambda_{2}\right)=s \times\left(\lambda_{1} \widetilde{c_{1}} z_{1} q_{1}+\lambda_{2} \widetilde{c_{2}} z_{2} q_{2}\right)+C S .
$$

The analysis for this case is similar to that of Section 4.1. In particular, (3)-(4) still apply. However, the effect of $\lambda_{i}$ on the FDI benefit needs to be modified. Here,

$$
\frac{\partial(F D I \text { Benefit })}{\partial \lambda_{i}}=\widetilde{c}_{i} z_{i} q_{i}-\lambda_{i} \widetilde{c}_{i} z_{i} \frac{2}{3 b} \frac{\partial C_{i}}{\partial \lambda_{i}}+\lambda_{j} \widetilde{c}_{j} z_{j} \frac{1}{3 b} \frac{\partial C_{i}}{\partial \lambda_{i}}
$$

As in Section 4.1, it can be shown that the optimal discriminatory LCR policy induces both firm 1 and firm 2 to undertake FDI, i.e., $\lambda_{i}^{*} \in\left[0, \lambda_{i}^{o}\right]$ for $i=1,2$. This simplifies (7) to

$$
\frac{\partial(F D I \text { Benefit })}{\partial \lambda_{i}}=\widetilde{c}_{i}\left(q_{i}-\frac{2}{3 b} \lambda_{i} \widetilde{c}_{i}+\frac{1}{3 b} \lambda_{j} \widetilde{c}_{i}\right)
$$

which decreases in $\lambda_{i}$ and is positive for small $\lambda_{i}$ and negative for large $\lambda_{i}$. For the same reason given in Section 4.1, we can easily see and we prove in the Appendix (B) that $\lambda_{i}^{*}=0$ for small $s, \lambda_{i}^{*}=\lambda_{i}^{o}$ for large $s$, and $\lambda_{i}^{*} \in\left(0, \lambda_{i}^{o}\right)$ for moderate $s$. By focusing on the most interesting case where both $\lambda_{1}^{*}$ and $\lambda_{2}^{*}$ take interior solutions (i.e., the case of moderate $s$ ), we establish Proposition 3.

Proposition 3: If technological upgrading is the main FDI benefit to the host country, then the optimal discriminatory LCR policy induces both multinational firms to undertake FDI. The optimal LCR for the more cost-efficient firm is higher than that for the less efficient firm if $s$ is not too large. Specifically,

$$
\lambda_{i}^{*}=\frac{2 a(3 s-2)-3(2 s-1) c_{i}+c_{j}}{4(3 s-1) \widetilde{c}_{i}} \in\left[0, \lambda_{i}^{o}\right] \text { and } \quad \lambda_{1}^{*}>\lambda_{2}^{*}
$$

where the comparison holds when $s<\left(4 a-2 \bar{c}-c_{1}-c_{2}\right) / 6(a-\bar{c})$.

Proof: See the Appendix (B). 
Recall from Section 4.1 that, when the host government cares about the employment benefit of FDI, it always sets a lower LCR for firm 1 than for firm 2. This result no longer holds when the government is concerned with the technological catching-up effect of FDI and $s$ is not too large. This sharp contrast can be understood as follows. Under the specification of FDI benefit in Section 4.1, the loss of consumer surplus from a higher $\lambda_{1}$ dominates the gain of FDI benefit, and hence the host government imposes a lower LCR on firm 1, to avoid large welfare losses. When the host government cares about the technological catching-up effect of FDI, however, the FDI benefit contributed by the more cost-efficient firm 1 becomes dominant, and hence the host government imposes a higher LCR on firm 1, to extract more welfare gains.

In this section, we have shown that the optimal discriminatory LCR always induces both firms to choose FDI. However, different degrees of LCR should be imposed on different firms. We would like to discuss here the implementability of the optimal policy and draw some testable implications from Propositions 2-3. According to the analysis of the optimal discriminatory policy in this section, two pieces of information are key to the design and implementation of the optimal policy. First, the host government needs to know the type of FDI benefit that the multinational firms bring to the country. Second, the government needs to identify which firm is the more cost-efficient one. The same information is also needed if we are to test the theory in the real world. We argue that this information can be obtained, at least indirectly. First, a close examination of the FDI process in a particular industry would reveal whether the FDI benefit includes mostly employment (it does if there is no technology licensing involved) or a combination of employment and technological upgrading (it does if technology licensing is involved). Second, the unit costs of production may not be directly observable, but they can be inferred from the firms' market shares. In particular, the more cost-efficient firm is expected to have a larger market share. Therefore, we should expect to see that when there is no technology licensing, the firm with a larger market share is offered a more favorable LCR policy; but when the FDI benefit is mainly from technology licensing, the firm with a larger market share is offered a less favorable LCR policy.

\section{Uniform LCR Policy}


While it is optimal from the host country's point of view to impose different LCRs on different multinational firms, a lower LCR is always preferred by the firms. If the firms strategically distort the market outcomes in order to receive a more favorable LCR policy, the market information is no longer useful for guiding the design of the optimal discriminatory LCR policy. Moreover, a discriminatory policy is often difficult to be monitored and enforced. Finally, in reality, governments may even be restricted from having discriminatory policies. For these reasons, it is appropriate to consider the case in which the host government is constrained to offer the same LCR policy to all multinational firms.

We denote the uniform LCR policy by $\lambda$. From Proposition 1, we know how an increase in the level of LCR affects the firms' choices of entry mode. Specifically, for $\lambda \leq \lambda_{1}^{o}$, both firm 1 and firm 2 engage in FDI; for $\lambda_{1}^{o}<\lambda \leq \lambda_{2}^{o}$, firm 1 chooses export while firm 2 engages in FDI; for $\lambda>\lambda_{2}^{o}$, both firms choose export. Therefore, we have

$$
C_{i}=\left\{\begin{array}{ll}
\lambda \bar{c}+(1-\lambda) c_{i} & \begin{array}{l}
\text { for } \lambda \leq \lambda_{i}^{o}, \\
c_{i}+t
\end{array} \quad \text { otherwise }
\end{array} \quad \text { and } \quad \frac{\partial C_{i}}{\partial \lambda}= \begin{cases}\widetilde{c}_{i} & \text { for } \lambda \leq \lambda_{i}^{o} \\
0 & \text { otherwise }\end{cases}\right.
$$

Intuitively, an increase in $\lambda$ pushes up a firm's cost of production so long as the firm chooses the FDI mode (for $\lambda \leq \lambda_{i}^{o}$ ), but it ceases to have any effect when the firm switches its mode from FDI to export (for $\lambda>\lambda_{i}^{o}$ ). It follows that the total output and consequently the consumer surplus decrease in $\lambda$ over $\left[0, \lambda_{2}^{o}\right]$, and they become constant for $\lambda>\lambda_{2}^{o}$. Formally,

$$
\frac{\partial C S}{\partial \lambda}= \begin{cases}-\left(\widetilde{c}_{1}+\widetilde{c}_{2}\right)\left(q_{1}+q_{2}\right) / 3 & \text { for } \lambda \leq \lambda_{1}^{o}, \\ -\widetilde{c}_{2}\left(q_{1}+q_{2}\right) / 3 & \text { for } \lambda_{1}^{o}<\lambda \leq \lambda_{2}^{o} \\ 0 & \text { otherwise }\end{cases}
$$

Therefore, if the host government is only concerned about the consumer surplus, it should set the LCR as low as possible. Also note that for $\lambda>\lambda_{2}^{o}$, neither firm 1 nor firm 2 undertakes FDI, and hence there is no FDI benefit. Therefore, the LCR should not be set so high that neither firm engages in FDI; that is, the optimal $\lambda^{*}$ must be in either $\left[0, \lambda_{1}^{o}\right]$ or $\left(\lambda_{1}^{o}, \lambda_{2}^{o}\right]$. But further characterizing the optimal LCR requires the specification of the welfare function.

\subsection{FDI benefit - employment}

We first consider the case where the host government cares about the employment benefit 
of FDI and chooses $\lambda$ to maximize

$$
W(\lambda)=s \times\left(\lambda \bar{c} z_{1} q_{1}+\lambda \bar{c} z_{2} q_{2}\right)+C S .
$$

To determine whether the optimal $\lambda^{*}$ is in the range of $\left[0, \lambda_{1}^{o}\right]$ or $\left(\lambda_{1}^{o}, \lambda_{2}^{o}\right]$, we need to compare the social welfare in these two ranges. However, the comparison is made complicated by the fact that the functional form of social welfare for $\lambda \in\left[0, \lambda_{1}^{o}\right]$ is different from that for $\lambda \in\left(\lambda_{1}^{o}, \lambda_{2}^{o}\right]$. Specifically, the welfare function for $\lambda \in\left[0, \lambda_{1}^{o}\right]$ is

$$
s \lambda \bar{c}\left(q_{1}+q_{2}\right)+\frac{1}{2} b\left(q_{1}+q_{2}\right)^{2}
$$

where $q_{1}$ and $q_{2}$ are the equilibrium outputs when both firms choose FDI, which are obtained using $C_{i}=\lambda \bar{c}+(1-\lambda) c_{i}$ in $(2)$; and the welfare function for $\lambda \in\left(\lambda_{1}^{o}, \lambda_{2}^{o}\right]$ is

$$
s \lambda \bar{c} q_{2}+\frac{1}{2} b\left(q_{1}+q_{2}\right)^{2}
$$

where $q_{1}$ and $q_{2}$ are the equilibrium outputs when firm 1 chooses export but firm 2 chooses FDI, which are obtained using $C_{1}=c_{1}+t$ and $C_{2}=\lambda \bar{c}+(1-\lambda) c_{2}$ in (2).

Using (9) and (10), it is straightforward to verify the following result: ${ }^{23}$ the consumer surplus in the range $\left[0, \lambda_{1}^{o}\right]$ is higher than that in the range $\left(\lambda_{1}^{o}, \lambda_{2}^{o}\right]$, but the FDI benefit in the range $\left[0, \lambda_{1}^{o}\right]$ may be higher or lower than that in the range $\left(\lambda_{1}^{o}, \lambda_{2}^{o}\right]$. This observation highlights the trade-off between a low $\operatorname{LCR}\left(\lambda \in\left[0, \lambda_{1}^{o}\right]\right)$ and a high $\operatorname{LCR}\left(\lambda \in\left(\lambda_{1}^{o}, \lambda_{2}^{o}\right]\right)$. If the government attempts to impose a high LCR, it has to strike a balance between a low consumer surplus and a potentially high FDI benefit.

To make our analysis interesting, we focus on the scenario in which the host government cares sufficiently about the FDI benefit, for otherwise it is always optimal for the government to set the LCR very low to minimize the losses in consumer surplus. ${ }^{24}$ Specifically, we assume that Condition 1 below holds.

Condition 1: $t$ is not too large to rule out the export mode and $s>\max \left\{s_{1}, s_{2}\right\}$, where

$$
s_{1} \equiv \frac{\widetilde{c}_{2}\left(2 a-c_{1}-c_{2}-2 t\right)}{3 \bar{c}\left(a+c_{1}-2 c_{2}-3 t\right)}
$$

\footnotetext{
${ }^{23}$ Lemma 1 in Qiu and Tao (1999) contains this result and a formal proof.

${ }^{24}$ We have a formal proof of this claim in Qiu and Tao (1999).
} 
and

$$
s_{2} \equiv \frac{\left(\widetilde{c}_{1}+\widetilde{c}_{2}\right)^{2} t+\widetilde{c}_{1}\left(2 a-c_{1}-c_{2}\right)\left(c_{1}+c_{2}-\bar{c}\right)}{2\left(\widetilde{c}_{1}+\widetilde{c}_{2}\right) t-\widetilde{c}_{1}\left(2 a-c_{1}-c_{2}\right)}
$$

Then, under Condition 1, the welfare (9) is maximized at $\lambda=\lambda_{1}^{o}$ and (10) is maximized at $\lambda=\lambda_{2}^{o}$. By comparing these two welfare levels, we obtain the optimal LCR $\lambda^{*}$.

Proposition 4: Suppose employment is the main FDI benefit and Condition 1 is satisfied. Then $\lambda^{*}=\lambda_{1}^{o}$ and both firms take FDI if $c_{2}$ is close to $c_{1}$ (i.e., if the two firms have similar costs of production). If, however, $c_{2}$ is not close to $c_{1}$ (i.e., if the two firms have very different costs), then $\lambda^{*}=\lambda_{2}^{o}$ and firm 1 exports while firm 2 takes FDI.

Proof: See the Appendix (C).

The intuition for Proposition 4 is given as follows and is a result of trade-off between high consumer surplus and low FDI benefit when the LCR is low, or low consumer surplus and possibly high FDI benefit when the LCR is high. First, note that since the government values the FDI benefit sufficiently (Condition 1), there is a tendency to set a higher LCR. But for $t$ not too large (Condition 1), $\lambda_{1}^{o}$ is small and so is $\lambda_{2}^{o}$ if the cost difference is small, i.e., if $c_{2}$ is close to $c_{1}$. Then, keeping the LCR low ensures large consumer surplus and raising $\lambda$ can easily lead to both firms to switch to the export mode, resulting in no FDI benefit. Thus, it is optimal to choose a low-level LCR, i.e., $\lambda^{*}=\lambda_{1}^{o}$. On the contrary, $\lambda_{2}^{o}$ is large when the cost difference is large, i.e., when $c_{2}$ is not close to $c_{1}$ (but then it is close to $\bar{c}$ ). In this case, the negative impact of raising the LCR so that the low-cost firm switches to exporting but the high-cost firm remains to take FDI is small. Hence, it is then optimal to set $\lambda^{*}=\lambda_{2}^{o}$.

\subsection{FDI benefit - technological upgrading}

Now we consider the case where the host government cares about the technological catchingup effect of FDI and chooses $\lambda$ to maximize

$$
W(\lambda)=s \times\left(\lambda \widetilde{c}_{1} z_{1} q_{1}+\lambda \widetilde{c}_{2} z_{2} q_{2}\right)+C S
$$


As shown earlier, the optimal $\lambda^{*}$ should be in either $\left[0, \lambda_{1}^{o}\right]$ or $\left(\lambda_{1}^{o}, \lambda_{2}^{o}\right]$. Further analysis of $\lambda^{*}$ for this case is quite similar to that of Section 5.1. In particular, the welfare function becomes

$$
\begin{gathered}
s \lambda\left(\widetilde{c}_{1} q_{1}+\widetilde{c}_{2} q_{2}\right)+\frac{1}{2} b\left(q_{1}+q_{2}\right)^{2} \text { for } \lambda \in\left[0, \lambda_{1}^{o}\right] \\
s \lambda \widetilde{c}_{2} q_{2}+\frac{1}{2} b\left(q_{1}+q_{2}\right)^{2} \text { for } \lambda \in\left(\lambda_{1}^{o}, \lambda_{2}^{o}\right] .
\end{gathered}
$$

Again, the consumer surplus in the range $\left[0, \lambda_{1}^{o}\right]$ is higher than that in the range $\left(\lambda_{1}^{o}, \lambda_{2}^{o}\right]$, but the FDI benefit in the range $\left[0, \lambda_{1}^{o}\right]$ may be higher or lower than that in the range $\left(\lambda_{1}^{o}, \lambda_{2}^{o}\right]$.

As in Section 5.1, we also focus on the scenario in which the host government cares very much about the FDI benefit. In particular, we assume:

Condition 2: $t$ is not too large to rule out the export mode and $s>\max \left\{s_{3}, s_{4}\right\}$, where

$$
s_{3} \equiv \frac{\widetilde{c}_{2}\left(2 a-c_{1}-c_{2}-t\right)-\widetilde{c}_{2} t}{3 \widetilde{c}_{2}\left(a+c_{1}-2 c_{2}+t\right)-12 \widetilde{c}_{2} t}
$$

and

$$
s_{4} \equiv \frac{\left(2 a-c_{1}-c_{2}\right)\left(\widetilde{c}_{1}+\widetilde{c}_{2}\right) \widetilde{c}_{1}-\left(\widetilde{c}_{1}+\widetilde{c}_{2}\right)^{2} t}{3 \widetilde{c}_{1}\left[\left(a-2 c_{1}+c_{2}\right) \widetilde{c}_{1}+\left(a+c_{1}-2 c_{2}\right) \widetilde{c}_{2}\right]-6 t\left[\left(\bar{c}-2 c_{1}+c_{2}\right) \widetilde{c}_{1}+\left(\bar{c}+c_{1}-2 c_{2}\right) \widetilde{c}_{2}\right]}
$$

Under this condition, (11) is maximized at $\lambda=\lambda_{1}^{o}$ and (12) is maximized at $\lambda=\lambda_{2}^{o}$. By comparing these two welfare levels, we obtain the optimal LCR $\lambda^{*}$.

Proposition 5: : Suppose technological upgrading is the main FDI benefit and Condition 2 is satisfied. Then $\lambda^{*}=\lambda_{1}^{o}$, and both firms take FDI if $c_{2}$ is close to $c_{1}$ (the two firms have similar costs of production), or if $c_{2}$ is close to $\bar{c}$ (the two firms have very different costs).

Proof: See the Appendix (D).

When the firms' cost difference is small, both Propositions 4 and 5 make the same policy recommendation of setting the LCR to the level $\lambda_{1}^{o}$, for the same reason. However, when the firms' cost difference is large, which is the case when $c_{2}$ is close to $\bar{c}$, the two propositions suggest different policy levels. To understand this difference, let us look at the intuition behind Proposition 5 for the case of large cost difference, in which $\lambda_{1}^{o}$ is small but $\lambda_{2}^{o}$ is large. In 
principle, although consumer surplus decreases as the government raises the LCR, it could be still desirable to have a high level of LCR if the government values the FDI benefit sufficiently highly. The intuition for not setting $\lambda^{*}=\lambda_{2}^{o}$ in the case of $c_{2}$ close to $\bar{c}$ is as follows. On the one hand, setting $\lambda^{*}=\lambda_{2}^{o}$ means very high LCR, which reduces consumer surplus a lot. On the other hand, as the less advanced multinational firm (i.e., firm 2) has a technology that is only slightly superior to those of local upstream industries, there is limited technological upgrading if the host government chooses a high enough LCR to induce that firm to choose FDI. As a result, it is optimal to set a low LCR, $\lambda^{*}=\lambda_{1}^{o}$, to just obtain the technological upgrading benefit from the more technologically advanced firm (firm 1).

Finally, we would like to explore some testable implications from Propositions 4-5 and the optimal uniform LCR policy implementation. As pointed out before, we can use observable market shares to infer the firms' cost difference, and technology licensing to infer whether technological upgrading is the main FDI benefit. Hence, if technology licensing does not occur and if the market shares of the multinational firms are not too different, according to Proposition 4, the host government should impose a low LCR on both firms (the implementation issue) and we expect to observe FDI by both firms (the empirical issue). If the market shares of the firms are very different, then the government should impose a high LCR on both firms (the implementation issue) and we should observe that the multinational firm that has a significantly higher market share will choose the export mode and the one having a lower market share will choose the FDI mode (the empirical issue). However, if the FDI benefit is mainly from technology licensing, then according to Proposition 5, the host government should impose a low LCR on both firms regardless of the market share difference (the implementation issue), and we expect to observe that both firms choose the FDI mode (the empirical issue).

It is also interesting to compare the optimal discriminatory LCR policy and the optimal uniform LCR policy. When the government uses discriminatory LCR policies, both firms are induced to choose the FDI mode and so the point is to see whether the more cost-efficient firm or the less cost-efficient firm receives a more favorable LCR policy. In contrast, under the uniform LCR policy, since the government must offer the same LCR to both firms, the focus 
is on whether both firms will be induced to choose the FDI mode, and it turns out that under certain conditions the more efficient firm chooses the export mode while the less efficient firm chooses the FDI mode. The main reason for such a difference between the two types of LCR policies is the conflict between the divergence in the costs of production among the multinational firms and the inflexibility of the uniform LCR policy. A testable implication of this is that the share of FDI output in total output is negatively related to the degree of uniformity of the LCR policy.

\section{Concluding Remarks}

This paper has made two main contributions to the FDI literature. First, it offers a partial explanation of why multinationals in the same industry may adopt different entry modes, namely FDI and export, to enter the same market. We emphasize the role of the LCR policy adopted by the host government towards FDI. We find that a firm with lower production efficiency is more likely to adopt the FDI mode over the export mode. Second, the paper characterizes conditions under which the host government's optimal uniform LCR policy results in both firms choosing the FDI mode or one firm choosing the FDI mode and the other the export mode. It also compares the optimal discriminatory LCRs designed for various multinational firms. Some useful and testable predictions are derived from these results.

As this paper is the first one to address the issue of MNEs' asymmetric entry modes and to derive optimal LCR policy under this framework, it inevitably makes many simplifying assumptions. Some of them may reduce the generality of the results obtained. They also suggest directions for future research. In particular, it would be interesting to examine multinational firms' entry modes and optimal LCR policies where the MNEs have different degrees of vertical integration or where their products have different qualities. Another direction of future work is to model explicitly how LCR policies affect technology transfer from developed to developing countries. 


\section{Appendix}

\section{A. Proof of Proposition 2}

We now state and prove a more general proposition which contains Proposition 2 as a special case (when the optimal LCRs are interior).

Proposition 2': There exist $\underline{s}_{i}$ and $\bar{s}_{i}$ such that:

(i) The optimal $\operatorname{LCR}\left(\lambda_{1}^{*}, \lambda_{2}^{*}\right)$ is characterized by the following:

$$
\lambda_{i}^{*} \begin{cases}=0 & \text { for } s \leq s_{i}, \\ \in\left(0, \lambda_{i}^{o}\right) & \text { for } \underline{s}_{i}<s<\bar{s}_{i}, \\ =\lambda_{i}^{o} & \text { for } s \geq \bar{s}_{i} .\end{cases}
$$

(ii) When $s \in\left(\underline{s}_{i}, \bar{s}_{i}\right)$ (i.e., when $\lambda_{i}^{*}$ is an interior solution), $\partial \lambda_{i}^{*} / \partial s>0$.

(iii) Comparison of the two optimal LCRs yields

$$
\begin{cases}\lambda_{1}^{*}=\lambda_{2}^{*}=0 & \text { for } s \leq \underline{s}_{2} \\ \lambda_{1}^{*}<\lambda_{2}^{*} & \text { for } s>\underline{s}_{2} .\end{cases}
$$

Proof. (i), (ii): Assuming an interior solution, then given any $\lambda_{j}$, from the first-order condition for $\lambda_{i}, \partial W / \partial \lambda_{i}=0$, we obtain

$$
\lambda_{i}=\frac{A_{i}+\lambda_{j} \Psi}{\Psi} .
$$

Note that given $\lambda_{j}, \lambda_{i}$ increases in $s$. Since $\lambda_{i}$ is also increasing in $\lambda_{j}$ as shown by (A1), the optimal $\lambda_{i}^{*}$ increases in $s$ whenever it is an interior solution. This shows the existence of $\underline{s}_{i}$ and $\bar{s}_{i}$. If both $\lambda_{1}^{*}$ and $\lambda_{2}^{*}$ are interior solutions, then solving the two equations $(i=1,2)$ in (A1) yields the optimal policy as given below

$$
\lambda_{i}^{*}=\frac{A_{i} \Psi_{j}+A_{j} \Psi}{\Psi_{1} \Psi_{2}-\Psi^{2}}
$$

where $\Psi_{i} \equiv\left(12 s \bar{c}-\widetilde{c}_{i}\right) \widetilde{c}_{i}, \quad \Psi \equiv 3 s \bar{c}\left(\widetilde{c}_{1}+\widetilde{c}_{2}\right)+\widetilde{c}_{1} \widetilde{c}_{2}$, and $A_{i} \equiv 3 s \bar{c}\left(a-2 c_{i}+c_{j}\right)-\left(2 a-c_{1}-c_{2}\right) \widetilde{c}_{i}$, $i=1,2$.

(iii): We now prove Proposition 2'(iii). Let us first consider the case when both $\lambda_{i}^{*}$ and $\lambda_{j}^{*}$ are interior solution and so they are determined by the first-order conditions. For convenience, we define $M S B_{i}\left(\lambda_{i}\right)=\partial(F D I$ Benefit $) / \partial \lambda_{i}$ and $M S C_{i}\left(\lambda_{i}\right)=\partial C S / \partial \lambda_{i}$. Then from (6) we have

$$
M S B_{i}(\lambda)=\frac{s \bar{c}}{3 b}\left[a-4 \lambda_{i} \bar{c}_{i}-2 c_{i}+\lambda_{j}\left(\widetilde{c}_{1}+\widetilde{c}_{2}\right)+c_{j}\right], \quad i=1,2,
$$

and from (4) we have

$$
M S C_{i}(\lambda)=\frac{\widetilde{c}_{i}}{3}\left(q_{1}+q_{2}\right)=\frac{\widetilde{c}_{i}}{9 b}\left(a-2 \lambda_{i} \widetilde{c}_{i}-2 c_{i}+\lambda_{j} c_{j}+c_{j}\right), \quad i=1,2 .
$$


Recall that given $\lambda_{j}$, the optimal $\lambda_{i}^{*}$ is given by $M S B_{i}\left(\lambda_{i}^{*}\right)=M S C_{i}\left(\lambda_{i}^{*}\right)$. If $M S B_{i}\left(\lambda_{i}^{\prime}\right)>(<$ ) $M S C_{i}\left(\lambda_{i}^{\prime}\right)$, then the optimal $\lambda_{i}^{*}>(<) \lambda_{i}^{\prime}$. We now define

$$
\begin{aligned}
\Delta(\lambda) & \equiv\left[M S B_{1}(\lambda)-M S C_{1}(\lambda)\right]-\left[M S B_{2}(\lambda)-M S C_{2}(\lambda)\right]=\Delta M S B(\lambda)-\Delta M S C(\lambda) \\
& =\frac{c_{2}-c_{1}}{9 b}\left\{3 s \bar{c}(3-4 \lambda)-\left[2 a-2 \lambda\left(\widetilde{c}_{1}+\widetilde{c}_{2}\right)-(1-\hat{\lambda})\left(c_{1}+c_{2}\right)\right]\right\},
\end{aligned}
$$

and have

$$
\frac{\partial \Delta}{\partial \lambda}=\frac{c_{2}-c_{1}}{9 b}\left[-12 s \bar{c}+2\left(\widetilde{c}_{1}+\widetilde{c}_{2}\right)\right]<0,
$$

which holds under the necessary and sufficient condition for $W\left(\lambda_{1}, \lambda_{2}\right)$ to be strictly concave. It can be checked that this condition is

$$
s>\frac{\widetilde{c}_{1}}{12 \bar{c}}, \quad 14 \widetilde{c}_{1} \widetilde{c}_{2}-\widetilde{c}_{1}^{2}-\widetilde{c}_{2}^{2}>0, \text { and } s>\frac{2 \widetilde{c}_{1} \widetilde{c}_{2}\left(\widetilde{c}_{1}+\widetilde{c}_{2}\right)}{\bar{c}\left(14 \widetilde{c}_{1} \widetilde{c}_{2}-\widetilde{c}_{1}^{2}-\widetilde{c}_{2}^{2}\right)}
$$

Furthermore, $\Delta(0) \leq 0$ if and only if $s \leq\left[2 a-(1-\hat{\lambda})\left(c_{1}+c_{2}\right)\right] / 9 \bar{c}$, which holds for large $a$ and $s \leq \bar{s}_{i}$. Therefore, $\Delta(\lambda)<0$ for all $\lambda>0$, which implies that when $M S B_{1}(\lambda)-M S C_{1}(\lambda)=0$, we still have $M S B_{2}(\lambda)-M S C_{2}(\lambda)>0$. That is, $\lambda_{2}^{*}>\lambda_{1}^{*}$.

Now let $s$ continue to decrease. Then the first $\lambda_{i}^{*}$ to be equal to zero must be $\lambda_{1}^{*}$, implying $\underline{s}_{1}>\underline{s}_{2}$. As $s$ continues to decrease slightly below $\underline{s}_{1}$, we argue that $\lambda_{2}^{*}$ is still positive. Note that even if we still used (A1) to determine $\lambda_{2}^{*}$, by continuity we would conclude that $\lambda_{2}^{*}$ is still positive. However, $\lambda_{2}^{*}$ should be determined in (A1) simply by setting $\lambda_{1}=0$, rather than using the negative $\lambda_{1}$. Thus $\lambda_{2}^{*}$ is larger than if a negative $\lambda_{1}$ were used, and so is positive. Since $\lambda_{1}^{*}$ is capped by $\lambda_{1}^{o}$, lower than $\lambda_{2}^{o}$ which caps $\lambda_{2}^{*}$, it is obvious that the inequality $\lambda_{1}^{*}<\lambda_{2}^{*}$ still holds when and after the upper corner solution is hit, at $\bar{s}_{1}$ or $\bar{s}_{2}$. This completes the proof of part (iii) of the proposition.

\section{B. Proof of Proposition 3}

We now state and prove a more general proposition which contains Proposition 3 as a special case (when the optimal LCRs are interior and $s$ is not too large).

Proposition 3': There exist $s_{i}^{L}, s_{i}^{H}$, and $s_{0}$ such that:

(i) The optimal $\operatorname{LCR}\left(\lambda_{1}^{*}, \lambda_{2}^{*}\right)$ is characterized by the following:

$$
\lambda_{i}^{*} \begin{cases}=0 & \text { for } s \leq s_{i}^{L}, \\ \in\left(0, \lambda_{i}^{o}\right) & \text { for } s_{i}^{L}<s<s_{i}^{H}, \\ =\lambda_{i}^{o} & \text { for } s \geq s_{i}^{H} .\end{cases}
$$

(ii) When $s \in\left(s_{i}^{L}, s_{i}^{H}\right)$ (i.e., when $\lambda_{i}^{*}$ is an interior solution), $\partial \lambda_{i}^{*} / \partial s>0$.

(iii) Defining $s_{0}=\left(4 a-2 \bar{c}-c_{1}-c_{2}\right) / 6(a-\bar{c})$, the comparison of the two optimal LCRs yields

$$
\begin{cases}\lambda_{1}^{*}=\lambda_{2}^{*}=0 & \text { for } s \leq s_{i}^{L}, \\ \lambda_{1}^{*}>\lambda_{2}^{*} & \text { for } s \in\left[s_{1}^{L}, s_{0}\right), \\ \lambda_{1}^{*}=\lambda_{2}^{*}>0 & \text { for } s=s_{0}, \\ \lambda_{1}^{*}<\lambda_{2}^{*} & \text { for } s>s_{0} .\end{cases}
$$


Proof. (i), (ii): The proof is similar to that of Proposition 2'. Using (4) and (8), we obtain the first-order conditions for interior $\lambda_{i}^{*}$ :

$$
\frac{\partial W}{\partial \lambda_{i}}=s \widetilde{c}_{i}\left(q_{i}-\frac{2}{3 b} \lambda_{i} \widetilde{c}_{i}+\frac{1}{3 b} \lambda_{j} \widetilde{c}_{j}\right)-\frac{1}{3}\left(q_{1}+q_{2}\right) \widetilde{c}_{i}=0, \quad i=1,2, i \neq j .
$$

Substituting $q_{1}$ and $q_{2}$ into the first-order condition yields

$$
\lambda_{i}=\frac{1}{(12 s-1) \widetilde{c}_{i}}\left[3 s\left(a-2 c_{i}+c_{j}\right)-\left(2 a-c_{1}-c_{2}\right)+\lambda_{j} \widetilde{c}_{j}(1+6 s)\right] .
$$

Solving the two equations in (A2) gives $\lambda_{i}^{*}$ as in Proposition 3. Define

$$
s_{i}^{L} \equiv \frac{4 a-3 c_{i}-c_{j}}{6\left(a-c_{i}\right)}, \quad s_{i}^{H} \equiv \frac{4 a-3 c_{i}-c_{j}-4 t}{6\left(a-c_{i}-2 t\right)} .
$$

Then $\lambda_{i}^{*}=0$ for $s \leq s_{i}^{L}, \lambda_{i}^{*}=\lambda_{i}^{o}$ for $s \geq s_{i}^{H}$, and $\lambda_{i}^{*} \in\left(0, \lambda_{i}^{o}\right)$ for $s \in\left(s_{i}^{L}, s_{i}^{H}\right)$. Differentiating $\lambda_{i}^{*}$ with respect to $s$ gives rise to

$$
\frac{\partial \lambda_{i}^{*}}{\partial s}=\frac{3\left(2 a-c_{1}-c_{2}\right)}{4 \widetilde{c}_{i}(3 s-1)^{2}}>0
$$

We now look at the case when not all $\lambda_{i}^{*}$ are interior solutions. Recall from the analysis preceding Proposition 3 that given $\lambda_{j}, \lambda_{i}$ increases in $s$. Since $\lambda_{i}$ is also increasing in $\lambda_{j}$ as shown by (A2), the optimal $\lambda_{i}^{*}$ increases in $s$ whenever it is an interior solution. This shows the existence of $s_{i}^{L}$ and $s_{i}^{H}$. This completes the proof of Proposition 3'(i) and (ii).

(iii): Using $\lambda_{i}^{*}$, direct comparison leads to $\lambda_{1}^{*}<\lambda_{2}^{*}$ iff $s>s_{0}$. In addition, it is easily checked that $s_{0}>s_{2}^{L}>s_{1}^{L}$ and $s_{0}<\min \left\{s_{1}^{H}, s_{2}^{H}\right\}$ for $t$ not too big. We now examine the case when one of $\lambda_{i}^{*}$ is not interior solution. As $s$ continues to decrease slightly below $s_{2}^{L}$, we argue that $\lambda_{1}^{*}$ is still positive. Note that if we still use (A2) to determine $\lambda_{1}^{*}$, by continuity $\lambda_{1}^{*}$ is still positive. However, $\lambda_{1}^{*}$ should be simply determined in (A2) by setting $\lambda_{2}=0$, rather than using the negative $\lambda_{2}$. As a result, $\lambda_{1}^{*}$ is larger than if a negative $\lambda_{2}$ is used and so is positive. This shows that the inequality $\lambda_{1}^{*}>\lambda_{2}^{*}$ still holds for $s \in\left(s_{1}^{L}, s_{2}^{L}\right]$. On the other hand, since $\lambda_{1}^{*}$ is capped by $\lambda_{1}^{o}$, lower than $\lambda_{2}^{o}$ which caps $\lambda_{2}^{*}$, it is obvious that the inequality $\lambda_{1}^{*}<\lambda_{2}^{*}$ still holds when and after the upper corner solution is hit, at $s_{1}^{H}$ or $s_{2}^{H}$. This completes the proof of part (iii) of the proposition.

\section{Proof of Proposition 4}

Here we only provide a proof for the case where $t$ is very large [in (i) below] or very small [in (ii)]. However, the proposition also applies to the case where $t$ does not take these extreme values. The proof of the intermediate $t$ case will be provided upon request or can be found in Qiu and Tao (1999).

Let us first give a preliminary result which is used in the proof of the proposition below. Suppose we define $U_{a}(\lambda)$ as the function given in (9) and $U_{b}(\lambda)$ as the function given in (10), and extend these two functions to the entire domain of $[0,1]$. Then, in addition to the result 
stated in the text after (9) and (10), we also know that within the range $\left[0, \lambda_{1}^{o}\right]$, both the FDI benefit and the consumer surplus of $U_{a}(\lambda)$ are higher than those of $U_{b}(\lambda)$. To see this, note that for $\lambda$ within the same range $\left[0, \lambda_{1}^{o}\right], C_{2}$ of $U_{a}$ is equal to $C_{2}$ of $U_{b}$, but $C_{1}$ of $U_{a}$ is lower than $C_{1}$ of $U_{b}$. Thus, the consumer surplus of $U_{a}$ is higher than that of $U_{b}$. On the other hand, for $\lambda \in\left[0, \lambda_{1}^{o}\right]$ the FDI benefit of $U_{a}$ and that of $U_{b}$ have the same $\lambda$, but it can be easily checked that $q_{1}+q_{2}$ of $U_{a}$ is higher than $q_{2}$ of $U_{b}$. Thus, the FDI benefit of $U_{a}$ is also higher than that of $U_{b}$.

(i) Suppose $t$ is so large that $t / \widetilde{c}_{1}=\lambda_{1}^{o}=1$. Then $\lambda_{2}^{o}$ is also capped at 1 . In this case, the comparison of $U_{a}(\lambda)$ and $U_{a}(\lambda)$ is really conducted in the same range of $\lambda:\left[0, \lambda_{1}^{o}\right]$ or $[0,1]$. Then from the preliminary result above we know that both the consumer surplus and the FDI benefit of $U_{a}\left(\lambda_{1}^{o}\right)$ are higher than those of $U_{b}\left(\lambda_{2}^{o}\right)$. Hence it is optimal to set $\lambda^{*}=\lambda_{1}^{o}$.

(ii-a) Suppose $t$ is so small that $\lambda_{1}^{o}$ is close to zero, say $\lambda_{1}^{o}=\varepsilon$. If $c_{2}$ is close to $c_{1}$, then $\lambda_{2}^{o}$ is also close to zero, namely $\lambda_{2}^{o}=\varepsilon$. In this case the comparison of $U_{a}\left(\lambda_{1}^{o}\right)$ and $U_{b}\left(\lambda_{2}^{o}\right)$ is really conducted in the same range of $\lambda:\left[0, \lambda_{1}^{o}\right]$ or $[0, \varepsilon]$. Then from the preliminary result above, we know that both the consumer surplus and FDI benefit of $U_{a}\left(\lambda_{1}^{o}\right)$ are higher than those of $U_{b}\left(\lambda_{2}^{o}\right)$. Hence it is optimal to set $\lambda^{*}=\lambda_{1}^{o}$.

(ii-b) If instead $c_{2}$ is close to $\bar{c}$, then $t /\left(\bar{c}-c_{2}\right)$ becomes very large and $\lambda_{2}^{o}$ is capped at 1 . Given that $s$ is sufficiently large (i.e., Condition 1), the host government cares almost exclusively about the FDI benefit when deciding $\lambda^{*}$. The FDI benefit of $U_{a}$ approaches zero because $\lambda_{1}^{o}=\varepsilon$, whereas the FDI benefit of $U_{b}$ (i.e., $\lambda_{2}^{o} s \bar{c} q_{2}$ or $s \bar{c} q_{2}$ ) is positive. Hence it is optimal to set $\lambda^{*}=\lambda_{2}^{o}$.

\section{Proof of Proposition 5}

The proof is similar to that for Proposition 4 except the part for the case of small $t$ and $c_{2}$ close to $\bar{c}$. Define $U_{a}(\lambda)$ as the function given in (11) and $U_{b}(\lambda)$ as the function given in (12), and extend these two functions to the entire domain of [0,1]. As $t$ becomes small, $\lambda_{1}^{o}$ approaches zero and hence the FDI benefit of $U_{a}$ approaches zero. Meanwhile, as $c_{2}$ approaches $\bar{c}, t / \widetilde{c}_{2}$ becomes very large and $\lambda_{2}^{o}$ is capped at 1 . But the FDI benefit of $U_{b}$ [i.e., $\lambda_{2}^{o} s\left(\bar{c}-c_{2}\right) q_{2}$ ] also approaches zero, because $\bar{c}-c_{2}$ approaches zero. Hence the comparison of $U_{a}$ and $U_{b}$ depends on the comparison of consumer surplus. From the result stated in the text after (11) and (12), we know that the consumer surplus of $U_{a}$ is higher than that of $U_{b}$. Thus we conclude that $\lambda^{*}=\lambda_{1}^{o}$.

\section{References}

Belderbos, R.B. and L. Sleuwaegen, 1997, "Local content requirements and vertical market structure", European Journal of Political Economy 13, 101-119. 
Brainard, L., 1993, "A simple theory of multinational corporations and trade with a trade-off between proximity and concentration", NBER Working Paper No. 4269.

Caves, Richard E., 1982, Multinational Enterprise and Economic Activity, Cambridge University Press (Cambridge, England).

Chao, C.C. and E.S.H. Yu, 1993, "Content protection, urban unemployment and welfare", Canadian Journal of Economics 26, 481-492.

Davidson, G., S.J. Matusz, and M.E. Kreinin, 1985, "Analysis of performance standards for direct foreign investment", Canadian Journal of Economics 16, 876-890.

Dixit, Avinash, 1988, "Anti-dumping and countervailing duties under oligopoly", European Economic Review 32, 55-68.

Dunning, J., 1977, "Trade, location of economic activity and MNE: A search for an eclectic approach", in B. Ohlin, P. Hesselborn, and P. Wijkman (eds.), The International Allocation of Economic Activity, Macmillan (London).

Dunning, J., 1981, International Production and the Multinational Enterprise, George Allen and Unwin (London).

EIU, 1996, "Local threats", Business China, 11 November, p. 3.

EIU, 1997, Multinational Companies in China: Winners and Losers, The Economist Intelligence Unit (Hong Kong).

Ethier, W., 1986, "The multinational firm", Quarterly Journal of Economics 101, 805-833.

Ethier, W. and J. Markusen, 1996, "Multinational firms, technology diffusion and trade", Journal of International Economics 41, 1-28.

Feinberg, Susan E., Michael P. Keane, and Mario F. Bognanno, 1998, "Trade liberalization and 'delocalization': new evidence from firm-level panel data", Canadian Journal of Economics 31(4), 749-777.

Grossman, Gene M., 1981, "The theory of domestic content protection and content preference", Quarterly Journal of Economics 96, 583-603.

Grossman, Gene M. and Elhanan Helpman, 1994, "Protection for sale", American Economic Review 84(4), 833-850.

Helpman, E., 1984, "A simple theory of international trade with multinational corporations", Journal of Political Economy 94(3), 451-471.

Hollander, A., 1987, "Content protection and transnational monopoly", Journal of International Economics 23, 283-297.

Horstmann, I. and J. Markusen, 1987, "Licensing versus direct investment: A model of internalization by the multinational enterprise", Canadian Journal of Economics 20, 464-481. 
Horstmann, I. and J. Markusen, 1992, "Endogenous market structures in international trade", Journal of International Economics 32, 109-129.

Horstmann, I. and J. Markusen, 1995, "Exploring new markets: Direct investment, contractual relationships, and the multinational enterprise", International Economic Review 32, 109-129.

Hymer, Stephen H., 1976, The International Operations of National Firms: A Study of Direct Foreign Investment, MIT Press (Cambridge, Mass.).

Krishna, K. and M. Itoh, 1988, "Content protection and oligopolistic interactions", Review of Economic Studies 55, 107-125.

Lahiri, Sajal and Yoshiyasu Ono, 1998, "Foreign direct investment, local content requirement, and profit taxation", The Economic Journal 108, 444-457.

Lopez-de-Silanes, F., J.R. Markusen, and T.F. Rutherford, 1996, "Trade policy subtleties with multinational firms", European Economic Review 40, 1605-1628.

Markusen, J., 1984, "Multinationals, multi-plant economies, and the gains from trade", Journal of International Economics 16, 205-226.

Markusen, James R., 1995, "The boundaries of multinational enterprises and the theory of international trade", Journal of Economic Perspectives 9(2), 169-189.

Markusen, James R., 1998, "Contracts, intellectual property rights, and multinational investment in developing countries", NBER Working Paper 6448.

Mody, Ashoka and Krishna Srinivasan, 1998, "Japanese and U.S. firms as foreign investors: Do they march to the same tune?", Canadian Journal of Economics 31(4), 778-799.

Qiu, Larry D., 1997, "China's foreign trade and investment: The case of automobile industry", Mimeo, Hong Kong University of Science and Technology.

Qiu, Larry D. and Zhigang Tao, 1999, "Export, foreign direct investment and local content requirement", Working Paper No. 99.7, Hong Kong University of Science and Technology.

Richardson, M., 1991, "The effect of content requirement on a foreign duopsonist", Journal of International Economics 31, 143-155.

Richardson, M., 1993, "Content protection with foreign capital", Oxford Economic Papers 24, 103-117.

UNIDO, 1986, Industrial Policy and the Developing Countries: An Analysis of Local Content Regulations, UNIDO/IS.606, 3 February.

Wonnacott, Paul, 1996, "The automotive industry in Southeast Asia", The World Economy 19(1), 89-112.

Woodard, Kim and Wei Zhu, 1994, "Revved and ready", The China Business Review, MarchApril, pp. 24-30. 